\title{
El uso de la epigrafía en ámbito político: el caso de las Res gestae divi Augusti
}

\section{The Use of Epigraphy in Political Sphere: the Case of Res gestae divi Augusti}

\author{
Giuditta CAVALLETTI \\ https://orcid.org/0000-0002-4178-1742 \\ Universidad Nacional Autónoma de México, México \\ giuditta.cavalletti@gmail.com
}

\begin{abstract}
RESUMEN: El propósito del presente artículo es ahondar en la composición del testamento político de Octaviano Augusto, enfocándonos en el medio epigráfico como instrumento de comunicación elegido por el emperador para dar a conocer las acciones llevadas a cabo en un momento complejo y complicado para la historia de Roma antigua, como fueron los años del fin de la república y los inicios de un nuevo gobierno impulsado por el mismo Octaviano. A lo largo de estas páginas, mostraremos cómo dicho documento puede considerarse también un medio de propaganda, pensado para dejar un retrato del optimus civis no sólo para los contemporáneos, sino también para la posteridad. Pongo el acento en este aspecto porque no todos los estudiosos consideran esta inscripción como un producto nacido de la pluma de Octaviano y especulan acerca de la existencia de alguien que pudo haber hecho el trabajo bajo comisión.
\end{abstract}

Palabras Clave: epigrafía latina, Octaviano Augusto, propaganda

ABstract: The purpose of this article is to delve into the composition of the political testament of Octavian Augustus, focusing on the epigraphic medium as an instrument of communication chosen by the emperor to publicize the actions carried out at a complex and complicated time for the history of ancient Rome such as the years of the end of the republic and the beginnings of a new government driven by the same Octavian. Throughout these pages, we will show how this document can also be considered a means of propaganda, designed to leave a portrait of the optimus civis not only for contemporaries, but also for posterity. I emphasize this aspect because not all scholars consider this inscription as a product born from the Octavian pen and speculate about the existence of someone who could have done the work on commission. 
KeYwords: Latin Epigraphy, Octavian Augustus, Propaganda

RECIBIDO: 09/10/2019 • ACEPTADO: 10/12/2019 • Versión FInAL: 29/12/2019

\section{LA CREACIÓN DE LAS RES GESTAE DIVI AUGUSTI}

En el año 13 d. C., a la edad de 76 años, justo un año antes de su muerte, Augusto entregó a las Vestales, sacerdotisas romanas, tres documentos testamentarios: el primero contenía el ceremonial para sus exequias, el segundo era la lista de obligaciones y recursos financieros y militares del Estado, y el tercero tenía el relato de sus memorias. Esto recuerda Suetonio, ${ }^{1}$ mientras Dión Casio menciona un cuarto documento con órdenes y recomendaciones para Tiberio y toda la comunidad respecto a la política externa e interna del imperio. ${ }^{2}$ Las disposiciones dejadas a las sacerdotisas acerca del recuento de sus empresas, conocido a lo largo de la historia como Res gestae divi Augusti y designado por Suetonio como Index a se rerum gestarum, eran que, una vez muerto el emperador, el texto fuera entregado a su heredero para que éste lo leyera ante el Senado y fuera posteriormente grabado en lastras de bronce fijadas en las columnas de la entrada del mausoleo, como inscripción que celebrara y recordara su figura, traducido al griego y enviado a varias partes del imperio.

La intención de un epígrafe bilingüe era que el mayor número posible de personas pudiera captar el mensaje ahí custodiado, a saber, que todo el actuar de Octaviano había sido una respuesta desinteresada ante los peligros enfrentados por Roma y que el hijo adoptivo de César estaba cumpliendo con la tarea que le había sido encomendada por el Senado y el pueblo romano. Finalmente, el 19 de agosto del 14 d. C., en Nola, la vida de Augusto llegó a su fin y, como había dispuesto, Tiberio dio lectura al testamento en calidad de heredero y ordenó que dicho texto se inscribiera en la entrada del mausoleo, al inicio denominado Tumulus Iuliorum, ${ }^{3}$ pensado como un

${ }^{1}$ Suet., Aug., 101, ed. 2009.

2 D.C., LVI, 32, ed. 2001.

${ }^{3}$ La construcción de este monumento se había comenzado en el 32 a. C., o bien después de la victoria de Accio, en el 29 a. C. en el campo Marcio, a las afueras de la ciudad (puesto que en el interior de ésta estaba prohibido realizar sepelios), lugar elegido por el Senado para custodiar los restos mortales de Sila y de los cónsules Ircio y Pansa. El grandioso complejo marmóreo, dominado por una enorme estatua de Augusto, dio inicio a la arquitectura funeraria en piedra y ladrillos que floreció en los tres siglos siguientes; dicho lugar se caracterizó por grandes jardines abiertos al público desde el 28 a. C., circundado por amplias columnatas y embellecido con dos obeliscos orientales provenientes de Egipto como botín de guerra y testimonio físico del dominio que había alcanzado Roma, gracias a la labor de conquista de Augusto. Cf. Guizzi 1996, p. 202. 
sepulcro para su dinastía. ${ }^{4}$ Durante varios años el monumento siguió en pie y custodió los restos mortales de otros emperadores como Vespasiano y Nerva, pero en el 410 d. C. las tropas bárbaras a las órdenes de Alarico invadieron Italia, saquearon el sitio y es muy probable que se llevaran las lastras de bronce. El mausoleo se convirtió entonces en una especie de pequeña montaña, conocida como mons Augustus, y en el siglo XII la familia de los Colonna decidió erigir allí una fortaleza llamada Augusta, varias veces atacada y finalmente destruida en 1241 por las tropas de Gregorio IX. ${ }^{5}$ Habrá que esperar hasta 1938 para tener nuevamente noticia de la presencia del texto en el territorio de Roma; en efecto, en ese momento, por voluntad de Benito Mussolini, se inscribió el epígrafe en la piedra del Ara pacis, para festejar el bimilenario del nacimiento de Augusto. Se trataba de un símbolo fundamental en la campaña de renacimiento del imperio realizada por el Duce, quien por medio de este recurso visual estableció un vínculo fuerte entre su figura y la del primer emperador romano. El texto utilizado fue el de la edición crítica de Concetta Barini de 1937, editado en la colección Scriptores graeci et latini, impulsada por el mismo Mussolini, y se distribuyó a lo largo de un muro de cuarenta metros dividido en siete paneles; hoy dicha inscripción es la única huella que nos queda del pabellón fascista. ${ }^{6}$

A pesar de haber perdido la huella epigráfica original de Roma, por azares del destino el relato imperial ha llegado hasta la modernidad, gracias al descubrimiento de testimonios epigráficos de las dos versiones (la latina y la griega), en la parte oriental del imperio, que han visto la luz a partir del siglo XVI y que han permitido, a través de la comparación con las noticias presentes en los autores antiguos, conocer y reconstruir el testamento de Augusto. Es muy interesante, en este sentido, el hallazgo del texto que aquí nos ocupa en el territorio de Ancyra. El 29 de marzo de 1555 una delegación de Fernando I de Habsburgo visitó dicha ciudad y encontró el testamento imperial en versión bilingüe en el templo de Augusto y Roma, consagrado en el año 25 a. C., como signo de gratitud por parte de la nueva provincia romana. Seguramente el hecho de que el texto fuera inscrito en la piedra permitió que se conservara a lo largo de los siglos y que no sufriera la misma suerte del original realizado en bronce. La colocación de ambas versiones, la griega en las paredes externas y la latina en la parte interna del templo, no fue casual, sino que respondió a la exigencia de que el texto fuera comprensible para la población cuya lengua propia era el griego, mientras que quienes

\footnotetext{
${ }^{4}$ Prohibió que se colocaran ahí las urnas con las cenizas de su hija y de su nieta, como castigo ejemplar por haber llevado una vida disipada, contraria al respeto del mos maiorum por él promovido.

${ }^{5}$ Botteri 2001, p. 136

${ }^{6}$ Rossini 2009.
} 
tenían acceso al interior, esto es, los sacerdotes y otros funcionarios, debían comprender sin problemas el latín, lengua oficial de la religión y administración del imperio romano.

Una primera edición del texto se dio a conocer en 1579, gracias al trabajo del jesuita Andrea Schott, quien había recibido una copia del original de manos de un integrante de la delegación; pero fue hasta 1695 cuando se produjo el primer texto filológicamente válido, el de Gronovius. El interés que suscitó el descubrimiento del documento, tanto por la autoridad de quien lo había escrito como por su contenido, se tradujo en varios viajes a Ancyra e hizo posible que, en 1701, Joseph Pitton de Tournefort encontrara la versión griega que, hasta aquel momento, había pasado inadvertida para quienes tuvieron acceso al templo, convirtiéndose así en el punto de partida para la edición del británico Hamilton en 1842.

Años más tarde, Napoleón III envió una expedición científica a Anatolia, cuyos hallazgos se han visto reflejados en la obra Exploration archéologique de la Galatie et de la Bithynie (2 vols., París, 1862-1872), realizada por George Perrot, quien se ocupó de la traducción en francés y del comentario, y por Edmond Guillarme, quien reprodujo un apógrafo de todo el texto latino y parte del griego, elaborando además dibujos sobre el original. Éste fue el texto utilizado por Theodor Mommsen para llevar a cabo su primera edición de las Res gestae en 1865, posteriormente incluida en el tercer volumen del Corpus Inscriptionum Latinarum (CIL), de 1873. ${ }^{7}$

En 1883, el investigador alemán trabajó en una segunda edición, comparando su texto con la versión presente en las 194 lastras de yeso que el cónsul alemán Karl Humann había realizado el año anterior durante su estancia en la ciudad oriental, a través de una operación de calco sobre el texto original, que se conserva en Berlín. Otros dos descubrimientos epigráficos permitieron reconstruir parte del texto y llenar las lagunas producidas por el hombre y por el paso del tiempo en el templo de Ancyra: un ejemplar griego fue encontrado inscrito en la base de un gran complejo monumental construido entre el 14 y el 19 d. C. en Apolonia, integrado por estatuas de Augusto, Tiberio, Livia, Germánico y Druso; mientras en Antioquía fueron descubiertos fragmentos marmóreos de la inscripción latina, fundamentales para aclarar algunas dudas en torno a la comprensión del texto.

Los tres ejemplares se conocen hoy como monumentum Ancyranum, monumentum Apolloniense y monumentum Antiochenum, y se consideran versiones fieles al original, probablemente traducido al griego en la misma Roma por la cancillería imperial y enviado a la parte oriental del imperio con la intención de que fuera conocido y entendido por la mayor parte de la población. Si bien no disponemos de datos confiables sobre quién pudo

\footnotetext{
${ }^{7}$ Cf. Botteri 2001.
} 
ocuparse de la traducción en lengua griega y a qué otras partes del mundo fue enviado el texto, suponemos, por la misma importancia que tiene este documento oficial, que fue traducido en la propia capital del imperio, donde era más fácil verificar que reflejara con exactitud el valor ideológico del texto latino, gracias a una elección semántica muy precisa.

El templo de Roma y Augusto en Ancyra ofrece la versión más completa de la inscripción bilingüe; edificado casi seguramente cuando el princeps aún vivía, en un lugar que ya había visto una construcción de tipo cultual, el monumento presenta la versión latina en las paredes del pronaos, dividida en tres columnas por un lado y tres por el otro. Las letras del título son más grandes respecto al demás texto y testimonian que se trata de una copia del ejemplar que en Roma Augusto había hecho transcribir en bronce. ${ }^{8}$ En la parte externa, muy visible al público, se localiza la versión griega, dividida en diecinueve columnas: el espejo epigráfico se encuentra en un estado de pésima conservación, debido a condiciones meteorológicas adversas, como las frecuentes lluvias ácidas o los repentinos cambios térmicos típicos de esta región que podrían llevar, en las próximas décadas, a la imposibilidad de una lectura clara del griego. ${ }^{9}$

El monumentum Apolloniense nos ha transmitido fragmentos del texto griego, dividido en siete columnas, que han permitido aclarar dudas y lagunas existentes en la versión del monumentum Ancyranum; mientras el monumentum Antiochenum, descubierto en 1914 por W. M. Ramsay en un lugar cercano a la hodierna Yalvaç, presenta huellas de una copia monumental de la versión latina, probablemente inscrita en el propileo que daba acceso a la platea tiberiana. ${ }^{10}$ Desafortunadamente, hasta el momento no se ha podido aclarar por qué se encontraron copias del testamento de Octaviano sólo en esa parte del imperio, más allá del carácter aleatorio que caracteriza a los descubrimientos epigráficos; tampoco tenemos noticia del número de copias que Tiberio encargó para que circularan y a qué lugares debían llegar. Se puede conjeturar que debían ser varios los destinos de las Res gestae por la intención misma del emperador de que se conociera su versión de los hechos, explicada también por la elección de que el texto fuera bilingüe; sin embargo, se trata sólo de una de las conjeturas más probables, que seguirá siendo tal hasta que contemos con un hallazgo, literario o epigráfico, que pueda desmentirla o confirmarla.

\footnotetext{
${ }^{8}$ Aug. Anc., ed. 2002: Rerum gestarum divi Augusti, quibus orbem terrarum imperio populi Romani subiecit, et inpensarum, quas in rem publicam populumque Romanum fecit, incisarum in duabus aheneis pilis, quae sunt Romae positae exemplar subiectum.

${ }^{9} \mathrm{Cf}$. Botteri 2006.

${ }^{10}$ Cf. Botteri 2003.
} 


\section{EL PROBLEMA DE LA DATACIÓN}

La cuestión acerca del momento histórico en el cual Augusto se dio a la tarea de escribir sus memorias sigue siendo un tema controvertido hasta el día de hoy. Algunos estudiosos ${ }^{11}$ piensan que el texto fue redactado en su juventud y defienden esta postura poniendo el acento en las referencias, presentes en la inscripción, en la vida política del emperador y en el hecho de que no hay ninguna otra mención después del honor que le concedió el Senado en el año 2 a. C., cuando fue nombrado pater patriae. Los detractores de esta posición afirman que, si esto fuera verdad, el texto resultaría mucho más breve que la versión definitiva y tendría una estructura diferente: "Le impensae e i paragrafi successivi non avrebbero trovato qui un posizionamento e la prima parte sarebbe stata solo delineata. Diversa dovrebbe essere l'organizzazione, con un motivo predominante su tutti, quello del vindex libertatis, incarnazione di tutte le virtù". ${ }^{12}$

Dicha problemática se origina a causa de la ambigüedad existente en las Res gestae con respecto al momento de su creación, puesto que, a lo largo de los treinta y cinco párrafos que componen la inscripción, encontramos dos referencias distintas: al inicio, ${ }^{13}$ Augusto declara haber escrito sus memorias cuando era cónsul por decimotercera vez, es decir, en el año 2 a. C., y al final ${ }^{14}$ afirma que tenía 76 años cuando emprendió dicha acción, esto es, en el año 13 d. C. Aquellos estudiosos que conciben el relato como obra de los primeros años de poder de Augusto justifican la segunda fecha como una intervención posterior hecha por Tiberio, al inscribir el texto, sin embargo, no resuelven la duda acerca del motivo de tal gesto. Por otro lado, tomar como certera sólo la segunda referencia significaría pensar que el autor decidió perpetuar nada más los inicios de su intervención en la vida política de Roma tras el asesinato de César, con detalles tan precisos que difícilmente podrían ser recordados después de tantos años sin tener un borrador escrito de ellos; tampoco nos explicaríamos el motivo de su silencio acerca de acontecimientos igualmente importantes, más cercanos al momento de la redacción de sus memorias.

Probablemente las dos referencias deben ser leídas como un testimonio de que Augusto trabajó el recuento de sus empresas a lo largo de los años,

\footnotetext{
${ }^{11}$ Por ejemplo, Kornemann 1918 asegura que Augusto pensó en las Res gestae en los años de construcción de su mausoleo, es decir, en el 28 a. C.

12 Guizzi 1999, p. 29.

${ }^{13}$ Aug. Anc., 4, ed. 2002: consul fueram terdeciens, cum scribebam haec, et eram septimum et tricensimum tribuniciae potestatis.

${ }^{14}$ Aug. Anc., 35, ed. 2002: qui sub signis meis tum militaverint, fuerunt senatores plures quam DCC, in iis qui vel antea vel postea consules facti sunt ad eum diem, quo scripta sunt haec, LXXXIII, sacerdotes circiter CLXX.
} 
revisando, corrigiendo y puliendo cada detalle para alcanzar el objetivo final, es decir, el de crear el retrato de sí mismo como defensor de la patria, restaurador de la paz y estabilidad del imperio. El hecho de que aluda a los primeros instantes de su vida política después de los idus de marzo del 44 a. C. se explica por la necesidad que tenía de mostrar cómo había llegado al poder y cómo esto se había dado por voluntad del pueblo y Senado romano, los cuales además le habían otorgado diferentes honores como agradecimiento por su labor, alejando las sospechas de que su intervención poco tuviera que ver con lo que siempre había declarado como justificante de su intervención, esto es, la realización de la res publica restituta: "Preoccupato di non rinnegare il programma e gli ideali che l'avevano portato a tanto, Augusto affermava la legittimità costituzionale della propria posizione e tendeva a ridimensionare il suo valore intrinseco, richiamando il principio della par potestas quale garanzia della libertà ritrovata". ${ }^{15}$

Teniendo en mente la voluntad de escribir su versión de los hechos, entendemos el cuidado que Octaviano reserva a la elección precisa de los términos, su manera de exaltar aquellos acontecimientos que sirvieran a la causa y captaran la benevolencia del público lector, dejando a un lado, o citando apenas, todos aquellos sucesos que pudieran ponerlo bajo una luz desfavorable. También la exactitud en la enumeración de los gastos tanto a favor del ejército como del pueblo, y el recuento de los censos ejecutados por el mismo emperador son un testimonio fundamental para considerar más probable la hipótesis de que Augusto retomó en varios momentos de su vida la escritura de sus memorias, a partir de una estructura planeada en una etapa temprana de su vida política. ${ }^{16}$ Es verosímil pensar que empezó a concebir y a trabajar en tal proyecto en estos años, entre su llegada al poder y el 23 a. C., pues sabemos que entonces estaba trabajando en una Autobiografia, que desafortunadamente no nos ha llegado, con el fin de justificar, a lo largo de los trece libros que la componían, sus elecciones en el campo político tras el asesinato de César, y explicar cómo había nacido y por qué se había podido asentar su poder. ${ }^{17}$ Para quienes piensan que la juventud representa un obstáculo para dicha hipótesis, es decir, que siendo joven Augusto concibiera redactar su testamento, es importante aclarar que era muy débil de salud y que en varias ocasiones, a lo largo de su vida, se encontró en peligro de muerte, como por ejemplo en el 24 a. C. cuando, al regresar de un viaje a España, cayó víctima de una grave enfermedad que hizo pensar a sus médicos que había llegado su hora final.

\footnotetext{
15 Guizzi 1996, p. 213.

${ }^{16}$ Así piensan Botteri 2006, Rossini 2009 y Syme 1989.

${ }^{17}$ Guizzi 1999, p. 31.
} 


\section{El CONTENIDO DE LAS RES GeSTAE DIVI AUGUSTI}

El texto de las Res gestae se presenta, en los diferentes testimonios que nos han llegado, de forma continua como era usual en los mensajes epigráficos, y ha sido dividido por la crítica moderna en párrafos para una lectura más ágil. Al llevar a cabo un análisis del relato es posible señalar algunos temas comunes que describen una realidad más amplia respecto a la que el título sugiere: en la primera parte, desde el primer párrafo hasta el decimocuarto, Augusto expone los honores aceptados y rechazados; en la segunda parte, desde el decimoquinto hasta el vigésimo cuarto, el autor recuerda los obsequios de dinero y tierras otorgados a los ciudadanos, las acciones a favor del pueblo romano y los arreglos monumentales de Roma; en la tercera parte, desde el párrafo vigésimo quinto hasta el trigésimo tercero, se ilustran las verdaderas Res gestae cumplidas por el emperador y, en los últimos dos párrafos, se definen los momentos más importantes de la carrera política de Augusto que culminan con el uso del término auctoritas. La introducción y el apéndice, añadido al final de la versión localizada en la ciudad de Ancyra y por eso conocido como addenda ancyrana, son el resultado de una intervención de Tiberio, en el original, al ordenar la transcripción en un medio epigráfico; al inicio, como mencionamos, se registra, en tercera persona, que se trata del recuento de las empresas que permitieron a Augusto sujetar el mundo al imperio del pueblo romano y, al final, encontramos un resumen de los gastos realizados, así como de los monumentos erigidos para la gloria de Roma. ${ }^{18}$

Leyendo el texto es evidente la intención que mueve al emperador a rendir cuentas, mediante ese recordatorio de su vida, tanto a los hombres de su tiempo como a la posteridad, de que todas sus acciones fueron en favor del pueblo y Senado romano y por voluntad de éstos; en efecto, su objetivo principal era demostrar que más que el poder personal le había interesado siempre el bien de la res publica y que, por esta razón, había asumido la tarea de restablecer la pax y la estabilidad después del asesinato de César y de los desórdenes que, a partir de este hecho, se habían generado. ${ }^{19}$ Era

\footnotetext{
18 Aug. Anc., addenda, ed. 2002: Summa pecuniae, quam dedit vel in aerarium vel plebei Romanae vel dimissis militibus denarium sexiens milliens. Opera fecit nova aedem Martis, Iovis Tonantis et Feretri, Apollinis, divi Iuli, Quirini, Minervae, Iunonis Reginae, Iovis Libertatis, Larum, deum Penatium, Iuv<entatis, Matris Magnae, Lupercal, pulvinar ad circum, curiam cum Chalcidico, forum Augustum, basilicam Iuliam, theatrum Marcelli, porticum Octaviam, nemus trans Tiberim Caesarum. Refecit Capitolium sacrasque aedes numero octoginta duas, theatrum Pompei, aquarum rivos, viam Flaminiam. Impensa praestita in spectacula scaenica et munera gladiatorum atque athletas et venationes et naumachiam et donata pecunia colonis municipiis oppidis terrae motu incendioque consumptis aut viritim amicis senatoribusque, quorum census explevit, innumerabilis.
}

${ }^{19}$ Braccesi 2013, pp. 117 ss. 
urgente, para Augusto, justificar su obra ante los ojos de los contemporáneos para dar una base sólida al consenso que había ido ganando, fundamental para seguir adelante sin obstáculos en su conquista del poder absoluto, fingiendo querer restaurar la república. Para tener una idea de la eficacia de su propaganda, será suficiente recordar cómo el mismo Cicerón, poco después de la muerte de César, en una sesión con los senadores, exhortó a apoyar al joven Octaviano en contra del enemigo de la patria, Antonio. En esos momentos el orador romano aún no había entendido quién era el verdadero peligro y obstáculo para la restauración de la estructura republicana y cuáles eran sus planes de conquista. Cuando Cicerón quiso alertar al Senado y al pueblo de la labor de Octaviano, ésta ya se hallaba en marcha, de tal manera que nadie lo apoyó y fue reducido al silencio sin que se creara una verdadera oposición frente a los planes del nuevo emperador. Aquí reside la inteligencia política de Augusto, pues en cada momento supo mostrar sus acciones como algo necesario para sus conciudadanos, quienes, al parecer, no tuvieron otra opción que dejar la suerte de la ciudad en sus manos, agradeciéndole su buena voluntad, sin ver (¿o sin querer ver?) sus verdaderas intenciones de tomar él mismo las riendas del poder. Para lograr su fin, Augusto se vio obligado a falsear, en algunas partes de su recuento, el curso real de la historia para justificar todo lo que hizo. Por ejemplo, al iniciar su relato afirma que el Senado, a la muerte de los cónsules en guerra, decidió nombrarlo cónsul; pero omite aclarar su intervención en el combate como parte contraria y también calla que había obligado a los senadores para que le dieran tal nombramiento, marchando armado en contra de Roma. ${ }^{20} \mathrm{El}$ episodio citado ilustra un detalle interesante que nos permite afirmar que este relato representa la versión oficial y no necesariamente real, de los hechos, contados por el mismo emperador, esto le permite sentar las bases para la consagración de su persona en su tiempo y, a través del medio epigráfico, en la eternidad.

Ahora bien, la mayoría de los estudiosos considera a las Res gestae como un unicum en la literatura latina por el tono seco y el uso de la primera persona muy poco usuales en los textos biográficos que nos han llegado. Por estos motivos, se ha estimado una buena opción no encasillar a fuerza a dicho texto en una sección predefinida, reconociendo su carácter particular que no admite cualquier definición ya establecida, y aceptando la ambigüedad de una obra donde las empresas de un hombre grande como Augusto encubren la sangre derramada, justificándola en nombre de la paz que se alcanzó.

En efecto, tras analizar en conjunto la obra de instauración de su poder personal podemos reconocer cómo el emperador, retomando el pasado, justi-

\footnotetext{
${ }^{20}$ Aug. Anc., 1, ed. 2002: populus autem eodem anno me consulem, cum consul uterque in bello cecidisset, et triumvirum rei publicae constituendae creavit.
} 
ficaba el nuevo orden y hacía hincapié en la continuidad que había que mantener con la época anterior, sin caer en los mismos errores de César, quien demostró abiertamente su sed de poder y, aunque "el poder de César Augusto era absoluto, y no había ningún contemporáneo que pudiera dudar de ello, su dominio era justificado por sus méritos, fundado en el consenso y templado por el sentido del deber". ${ }^{21}$ En esta afirmación de Ronald Syme radica, a mi juicio, el logro más grande de Augusto, pues leyendo su testamento y las diversas fuentes literarias e históricas de la época se entrevé que Octaviano llegó a ser Augusto porque ante la opinión pública logró afirmar su dominio como el resultado de sus méritos en la defensa de la república, una misión que las dos instituciones más importantes de la ciudad le habían asignado y, finalmente, un suceso inevitable en el desenlace de los eventos. Recordemos cómo, en el 27 a. C., frente a los senadores reunidos, decidió remitir todos aquellos poderes que nadie le había concedido, sino que él mismo había usurpado; se trataba de una maniobra arriesgada, pero calculada, necesaria para que su posición fuera, ahora sí, legitimada por las autoridades. ${ }^{22}$ Logró realizar sus expectativas gracias al consenso que supo generar, a lo largo de los años, a través de una propaganda política cuyo intento era justamente mostrarlo como el único personaje capaz de guiar a Roma fuera de los abismos de las guerras civiles, reivindicar su antiguo esplendor y su predominio en el mundo. Por estos motivos no coincido con aquellos estudiosos, para quienes Syme es un ejemplo a seguir, que etiquetan este periodo como el propio de una revolución: como argumenta Guizzi, ${ }^{23}$ para que pueda hablarse de este tipo de proceso se necesitaría un cambio radical en el status quo y/o que una o más personalidades subvirtieran el orden establecido, situación que no se da con Augusto, precisamente porque éste logra pasar de la república al dominio absoluto sin que se registre una revuelta del pueblo, gracias a un plan bien urdido para captar la benevolencia de los ciudadanos. Si bien es posible conjeturar que hubo quienes intuyeron su verdadera voluntad, esto no se resolvió con una inconformidad patente que diera paso a un enfrentamiento entre dos facciones, panorama habitual cuando se realiza una transformación radical. Por eso, es posible afirmar que la revolución no se produjo entre las masas, sino dentro de las instituciones que, manteniendo en apariencia sus características de siempre, perdieron su razón de ser. La propia elaboración de las Res gestae como legado para los contemporáneos y para la posteridad es un elemento fundamental en el proyecto de asegurar la continuidad de la labor empezada en vida y que era necesario preservar. Por esta razón considero que fue Au-

\footnotetext{
${ }^{21}$ Syme 1989, p. 318.

${ }^{22}$ Fraschetti 1998, pp. 56-57.

${ }^{23}$ Guizzi 1974, pp. 9 ss.
} 
gusto quien pensó en la transcripción de sus empresas, incluidos todos los elementos que componen el texto, así como en la decisión de grabarlo en la entrada de su mausoleo y enviarlo a diferentes provincias del imperio. Pongo el acento en este aspecto porque no todos los estudiosos consideran esta inscripción como un producto nacido de la pluma de Octaviano y especulan acerca de la existencia de alguien que pudo haber hecho el trabajo por encargo. A mi juicio, la conformación misma del texto - lo que calla y lo que enfatiza - es una buena pista para pensar que quien creó y probablemente escribió el epígrafe fue el propio emperador:

Il taglio del documento, la natura personale e giustificante dell'esposizione, la scelta degli eventi, le sottolineature, i silenzi, le ambiguità, le dichiarazioni ingannevoli o addirittura false non potevano essere il risultato di precise indicazioni fornite a uno scrittore fantasma e fedelmente eseguite. ${ }^{24}$

\section{El testamento DE OCTAVIANO COMO InStRUMENTO DE PROPAGANDA}

A través de las palabras y de las imágenes, presentes en los monumentos erigidos en toda la Urbe y en varias partes del imperio, así como en las obras de los autores cercanos a él que conformaban el círculo de Mecenas, Augusto fue convenciendo a la ciudadanía de que su intervención en la suerte política del pueblo romano había sido necesaria y dictada por las circunstancias gravísimas en las que se hallaba la república y que él era el único personaje del panorama político que había sido capaz de salvar al pueblo de las guerras internas y nuevamente dio fuerza y esplendor a Roma. Por eso considero el relato de sus memorias como un elemento fundamental de su propaganda, un testimonio de la exigencia continua que sentía de justificar y legalizar sus acciones frente a sus contemporáneos, pensando también en las generaciones futuras. Su lectura manifiesta ante nuestros ojos la vida de un personaje que ha dedicado sus energías a enfrentar los problemas urgentes que vivía en ese momento histórico el pueblo romano, subrayando la manera en la cual realizó sus acciones, es decir, en armonía con el Senado y la ciudadanía que rogaban, constantemente, su intervención en el destino de Roma.

El estilo de Augusto nos aclara mucho la función comunicativa y el fin propagandístico de su testamento, pues decide sintetizar los hechos que considera más significativos al usar un tono que parece lo más objetivo posible, utilizando un léxico político y técnico muy preciso para llegar directamente al punto sin recurrir a construcciones largas o complejas, prefiriendo una

\footnotetext{
${ }^{24}$ Guizzi 1999, p. 37.
} 
locutio simple y elegante que refleja claridad en la exposición y permite centrar la atención en los acontecimientos y no en cómo son contados. Gracias a este tipo de elaboración de su legado, Octaviano "costruì l'immagine di se stesso, delle sue imprese e del suo optimus status che la storia riceverà alla fine, per due millenni, grazie al taglio sottile e incisivo della sua prosa e - quanto all'intensità persuasiva - al tono inimitabile, falsamente basso, insinuante e, quando serve, obiettivo". 25

Augusto no elige un público específico a quien vaya dirigido su texto, prefiere referirse a todo romano y habitante del imperio, y esta intención se explica bien con el deseo de que el epígrafe fuera traducido al griego y enviado a diferentes lugares, donde la mayoría no conocía al emperador y sus empresas o, si esto llegaba a suceder, era a través de los relatos hechos por terceras personas. Otro elemento interesante de la prosa de Octaviano es la intención de no romper con el pasado, cuidándose de no cometer errores de presunción, logrando abrir camino a un nuevo orden sin destruir la tradición, sino sujetándose fuertemente a ella, mediante un llamado continuo al mos maiorum y al poder decisivo del Senado y del pueblo en todo lo relativo a sus acciones, llevadas a cabo por el bien de estas dos entidades; en resumidas cuentas, "si tratta della restaurazione della legalità repubblicana attraverso il recupero della reverentia verso il mos maiorum, saggiamente generica" ${ }^{26}$

La ideología del principado, entendida como la suma de los principios que rigen el poder, radica en esa imagen del princeps como el optimus civis, quien asume la responsabilidad de tomar sobre sí las riendas para salvar a Roma de la destrucción a la que la estaban llevando los conflictos internos que se agravaron con la muerte de César. La propaganda urdida es tan eficaz que, leyendo el resumen, el lector casi se va olvidando de quién fue realmente Octaviano, cuál fue el verdadero rol que desempeñó en las transformaciones de este tiempo, cómo protagonizó el mismo conflicto que afirmaba querer resolver; en fin, cuáles fueron las verdaderas acciones que llevó a cabo para lograr asentar su excepcional poder y cómo todo esto tiene que ver muy poco con el recuento presente en las Res gestae. La habilidad en la construcción del tejido narrativo se muestra en las diversas partes que componen dicho texto y que se entrelazan bien entre ellas para conseguir su objetivo; se trata de una alternancia de breves pinceladas, como por ejemplo en el segundo párrafo cuando recuerda la venganza de su padre y en sólo dos líneas utiliza palabras de fuerte impacto emotivo como trucidaverunt y facinus, junto con descripciones muy precisas. ${ }^{27} \mathrm{O}$ pensemos en los números que cita al hablar de los

${ }^{25}$ Canali 2002, p. 42.

${ }^{26}$ Guizzi 1999, p. 50.

${ }^{27}$ Aug. Anc., 2, ed. 2002: Qui parentem meum trucidaverunt, eos in exilium expuli iudiciis legitimis ultus eorum facinus et postea bellum inferentis rei publicae vici bis acie. 
censos $^{28}$ o la mención de los triunfos u honores concedidos por el Senado, ${ }^{29}$ así como los silencios o verdades a medias acerca de acontecimientos embarazosos por el fin que se estaba persiguiendo, como en el caso de la derrota de Teutoburgo, sabiamente omitida en el párrafo $30 .{ }^{30}$ Todos estos elementos le permiten ilustrar las diferentes cualidades que lo caracterizan y preparan el camino a la exaltación plena que se realiza en el momento en que nos recuerda que los propios senadores le reconocieron aquellas virtudes a las que alude a lo largo de todo su relato y decidieron grabarlas en un escudo que le fue donado para gloria de su persona. ${ }^{31}$ Estas características lo acercan al ideal del ciudadano constantemente preocupado por el bien de lo que restaba de la república, ocupado en hacer todo lo posible para dar nuevamente estabilidad a las instituciones, poniéndose a su servicio como si no tuviera otro fin en su vida. En efecto, la virtud, la clemencia, la justicia y la piedad que le son reconocidas representan "il simbolo del principato stesso, poiché nell'elenco stesso delle virtù si trova la dimensione umana, e non solo mistica o carismatica, del principato". 32 Justamente esta caracterización humana de Augusto es la que le permite acercarse a sus conciudadanos y fundamentar el intento de ser considerado un ejemplo a seguir en el presente y en el futu-

${ }^{28}$ Aug. Anc., 8, ed. 2002: Patriciorum numerum auxi consul quintum iussu populi et senatus. senatum ter legi. et in consulatu sexto censum populi conlega M. Agrippa egi. lustrum post annum alterum et quadragensimum feci. quo lustro civium Romanorum censa sunt capita quadragiens centum millia et sexaginta tria millia. tum iterum consulari cum imperio lustrum solus feci C. Censorino et C. Asinio cos., quo lustro censa sunt civium Romanorum capita quadragiens centum millia et ducenta triginta tria millia. et tertium consulari cum imperio lustrum conlega Tib. Caesare filio meo feci Sex. Pompeio et Sex. Appuleio cos., quo lustro censa sunt civium Romanorum capitum quadragiens centum millia et nongenta triginta et septem millia. legibus novis me auctore latis multa exempla maiorum exolescentia iam ex nostro saeculo reduxi et ipse multarum rerum exempla imitanda posteris tradidi.

${ }^{29}$ Valga como ejemplo Aug. Anc., 4, ed. 2002: Bis ovans triumphavi et tris egi curulis triumphos et appellatus sum viciens et semel imperator, decernente pluris triumphos mihi senatu, quibus omnibus supersedi. laurum de fascibus deposui in Capitolio votis, quae quoque bello nuncupaveram, solutis. ob res a me aut per legatos meos auspicis meis terra marique prospere gestas quinquagiens et quinquiens decrevit senatus supplicandum esse dis immortalibus. dies autem, per quos ex senatus consulto supplicatum est, fuere DCCCLXXXX. in triumphis meis ducti sunt ante currum meum reges aut regum liberi novem. consul fueram terdeciens, cum scribebam haec, et eram septimum et tricensimum tribuniciae potestatis.

${ }^{30}$ Aug. Anc., 30, ed. 2002: Pannoniorum gentes, quas ante me principem populi Romani exercitus nunquam adit, devictas per Ti. Neronem, qui tum erat privignus et legatus meus, imperio populi Romani subieci protulique fines Illyrici ad ripam fluminis Danuvi. citra quod Dacorum transgressus exercitus meis auspicis victus profligatusque est, et postea trans Danuvium ductus exercitus meus Dacorum gentes imperia populi Romani perferre coegit.

${ }^{31}$ Aug. Anc., 34, ed. 2002: quo pro merito meo senatus consulto Augustus appellatus sum et laureis postes aedium mearum vestiti publice coronaque civica super ianuam meam fixa est et clupeus aureus in curia Iulia positus, quem mihi senatum populumque Romanum dare virtutis clementiaeque iustitiae et pietatis causa testatum est per eius clupei inscriptionem.

${ }^{32}$ Guizzi 1974, p. 141. 
ro, finalidad perseguida en cada momento de su vida, a través de un llamado continuo para retomar las buenas costumbres que habían sido abandonadas en el último período de la historia romana.

Es verosímil pensar que sus memorias no lograron convencer enteramente a sus contemporáneos, a sus detractores, a quienes conocían el curso real de la historia de su época; sin embargo, es indudable la fuerza persuasiva que domina todo el relato, que debió crear un buen recuerdo del personaje allí mencionado en el ánimo de la población que vivía lejos del centro del poder, que no estaba familiarizada con el verdadero desarrollo y los pormenores de los acontecimientos políticos ahí relatados. En tiempos modernos nuestra apreciación es más objetiva y desencantada, por el conocimiento que tenemos de la verdadera política de Augusto y de sus consecuencias en la historia de Roma. Nos acercamos a las Res gestae sin considerarlas un testimonio fidedigno de la historia como realmente se ha desarrollado, sino concibiéndolas como un elemento fundamental en la creación de la propaganda realizada en torno a la figura de Octavio, pensada con el objetivo de trazar un perfil que testimoniara su buena voluntad en el trabajo ejecutado a favor de la salvación de los romanos.

Por estos motivos una lectura atenta y enfocada en las palabras utilizadas, en la disposición de los temas y en el silencio intencional acerca de acontecimientos fundamentales en la transformación que sufrió Roma en este paso de la república al imperio, se convierte en una herramienta para descifrar dicha propaganda, dejando al descubierto la suspicacia del autor y la retórica que subyace en todo el discurso. El propósito es ser recordado de manera benévola por quienes se darán a la tarea de juzgar su conducta y sentarán las bases para la consagración de su persona, ya empezada con la asignación, por parte del Senado, del título de Augustus. Por este motivo tiene mucha importancia y se insiste, a lo largo del relato, en rememorar las obras realizadas a favor del pueblo romano, tanto monumentos erigidos para embellecer y honrar a la ciudad de Roma (párrafos 19-21), como acciones militares (recordadas con muchos detalles desde el párrafo 26 hasta el 33) llevadas a cabo para asegurar la paz y tranquilidad y para acrecentar el dominio romano en diferentes partes del imperio.

Por último, el análisis de la obra en conjunto permite reconocer la presencia de tres dimensiones retóricas ${ }^{33}$ que cumplen con el intento de convencer y conmover el ánimo (movere animos) de los lectores u oyentes del epígrafe:

a) Una constante justificación de su política a lo largo de todo el texto.

b) La intención de crear un vínculo fuerte entre la persona del emperador y todos los ciudadanos, tanto de Roma como de las provincias, que representan al público inmediato al que va dirigido su testamento.

${ }^{33}$ Cf. Lauer 2004, p. 426. 
c) La presencia de la auctoritas interpretada como virtud religiosa fundamental y presentada como motivo de todas las decisiones de Octaviano.

Como ya señalamos, Augusto necesitaba legitimar y justificar su posición extraordinaria dentro del panorama político romano y decidió hacerlo a través de este testamento tan peculiar, reconociendo que la palabra escrita tiene un poder definitivo y, bien utilizada, puede llevar a quien la lea o la escuche a creer firmemente en algo totalmente extraño a su anterior sentir. El consensus es la base de la ideología que Octaviano va construyendo y es el elemento gracias al cual puede ocultar su verdadero plan: el deseo de reunir en sus manos todo el poder, mostrándose, al contrario, como un ciudadano preocupado por el bienestar de la república y que obedece la voluntad de aquellas entidades que le confiaron el destino de Roma.

En esta clave hay que interpretar el acento que Octaviano pone en sus memorias, al recordar cómo rechazó todos los nombramientos que le ofrecieron a lo largo de los años para que interviniera en la vida política romana, pues dichos nombramientos lo hubieran acercado al fantasma de César y habrían sido vistos como señal de la voluntad de alcanzar el poder absoluto, poniendo en serio riesgo el cumplimiento de su plan. Es ésta la explicación que da por haber rechazado la dictadura ${ }^{34}$ y el consulado permanente o renovable cada año; ${ }^{35}$ cuando asume la sobreintendencia de la anona, cargo que representaba también una violación a las costumbres de los antepasados, sostiene que fue "obligado" por la gravísima carestía que azotaba Roma, justificándose con el hecho de que la gravedad de la situación lo exoneraba de ser considerado culpable de otra cosa que no fuese la preocupación por la salvación del pueblo.

Lo anterior es un buen ejemplo de la retórica empleada por el príncipe que sabe utilizar el mismo discurso para justificar una acción o condenarla, gracias a la disposición de los argumentos, al anticiparse a las posibles objeciones que un lector pudiera hacerle frente a un sinsentido evidente, como en este caso. Se trata de una demostración clara de que Augusto pensaba constantemente en la recepción, por parte del público, de sus palabras y se preocupaba para que éstas reflejaran siempre una coherencia que fuera intachable e irreprensible.

\footnotetext{
${ }^{34}$ Aug. Anc., 5, ed. 2002: Dictaturam et absenti et praesenti mihi delatam et a populo et a senatu M. Marcello et L. Arruntio cos. non recepi.

${ }^{35}$ Aug. Anc., 5, ed. 2002: consulatum quoque tum annuum et perpetuum mihi delatum non recepi.
} 


\section{Conclusiones}

Todos los elementos mencionados en estas páginas me han llevado a considerar a las Res gestae como un instrumento directo de la propaganda y de la ideología de Augusto, quien preparó con este documento el camino a la celebración eterna de su persona y la posibilidad de que su forma de gobierno durara después de su desaparición del panorama político. Su propósito fue consagrar su figura como la del defensor patriae, personaje que obró siempre para bien y a favor de Roma y de sus ciudadanos, restableciendo las antiguas normas que regían la república y por eso merecedor, como él mismo afirma, ${ }^{36}$ de los honores que le otorgaron las dos máximas instituciones romanas.

El recorrido realizado demuestra que el testamento político de Augusto se puede considerar un claro ejemplo del uso que en Roma antigua se hizo de la epigrafía como una herramienta para vehicular un mensaje de celebración, memoria y propaganda, pensado para la eternidad y a la vista de la comunidad a la que estaba destinado.

\section{BIBLIOGRAFÍA}

\section{Fuentes antiguas}

Dión CASIO, Historia Romana, trad. y notas José María Candau Morón y María Luisa Puertas Castaños, Madrid, Gredos (Biblioteca Clásica Gredos, 325), 2001. Ottaviano, Augusto, Res Gestae divi Augusti, trad. Luca Canali, Milano, Mondadori, 2002.

Suetonio, Vida de los Césares, trad. Gonzalo García y Cecilia Belza, Barcelona, Crítica, 2009.

\section{Fuentes modernas}

Botteri, Paola, "Missione in Turchia: il monumentum Ancyranum", Quaderni di Storia, 54, 2001, pp. 133-148.

Botteri, Paola, "L'integrazione mommseniana a Res Gestae Divi Augusti 34,1 Potitus rerum omnium e il testo greco", Zeitschrift für Papyrologie und Epigraphik, 144, 2003, pp. 261-267.

Botteri, Paola, "Res Gestae Divi Augusti”, 2006, http://www2.units.it/ancyra/resGestae.htm (08/09/2019).

Braccesi, Lorenzo, Augusto. La vita raccontata da lui stesso, Napoli, Edises, 2013.

\footnotetext{
${ }^{36}$ Así se expresa en Aug. Anc., 34, ed. 2002: pro merito meo.
} 
FraschetTI, Augusto, Augusto, Roma-Bari, Laterza, 1998.

GuIzzI, Francesco, Il principato tra 'res publica' e potere assoluto, Napoli, Jovene, 1974.

GuIzzi, Francesco, "Res gestae. Bilancio di quarant'anni di governo", en Francesco Milazzo (a cura di), Res publica e princeps. Vicende politiche, mutamenti istituzionali e ordinamento giuridico da Cesare ad Adriano, Napoli, Edizioni Scientifiche Italiane, 1996, pp. 201-217.

Guızz, Francesco, Augusto: la politica della memoria, Roma, Salerno, 1999.

Kornemann, Ernst, "Neues zum Monumentum Ancyranum", Klio, XV, 1918, pp. 214-215.

LAUER, Ilon, "Ritual and power in Imperial Roman Rhetoric", Quarterly Journal of Speech, 90/4, November, 2004, pp. 422-445.

Rossini, Orietta, Res Gestae divi Augusti, Roma, Gangemi, 2009.

Syme, Ronald, La revolución romana, Madrid, Taurus, 1989.

$$
* * *
$$

Giuditta Cavalletti es licenciada en Letras Clásicas por la Università di Bologna, maestra y doctora en Letras por la Universidad Nacional Autónoma de México. Es investigadora en el Centro de Estudios Clásicos del Instituto de Investigaciones Filológicas de la UNAM. Imparte las asignaturas de Historia de Roma e Introducción a la Epigrafía Romana en el Colegio de Letras Clásicas de la FFYL (UNAM). Se dedica al estudio de la epigrafía latina, entendida como un medio de comunicación y una herramienta de propaganda, en relación con el ámbito político y religioso del mundo romano, y a la recepción de motivos clásicos en el mundo moderno. Ha participado en coloquios y congresos nacionales e internacionales en los cuales ha presentado trabajos relacionados con su línea de investigación, tanto principal como secundaria. 